\title{
US expects energy savings through smart manufacturing
}

$\mathrm{M}$ anufacturing has been a topic of interest in the materials community lately with significant focus on advanced and high-tech materials manufacturing. A second area that is poised to have a sizable impact on the manufacturing sector in the United States is smart manufacturing. A bill, titled the Smart Manufacturing Leadership Act (SMLA), seeks to "transform the manufacturing sector and the use by the manufacturing sector of energy, water, raw materials, and labor ... [which] will result in savings in electricity, natural gas, transportation fuels, chemical feedstocks, and many other fuels."

The bill was first introduced in the US Senate in April 2015 by Senator Jeanne Shaheen (D-N.H.), and has since gained support in both the Senate and the House of Representatives. In June 2015, Senator Lamar Alexander (R-Tenn.) joined Senator Shaheen as a co-sponsor of the senate version of the bill (S.1054) and Representative Peter Welch (D-Vt.) introduced an identical version of the bill in the House (H.R. 3266) in July 2015.

The term smart manufacturing is defined within the bill as "a set of advanced sensing, instrumentation, monitoring, controls, and process optimization technologies and practices that merge information and communication technologies with the manufacturing environment for the real-time management of energy, productivity, and costs across factories and companies." As smart manufacturing practices are implemented, production efficiencies increase, which in turn improves competitiveness of the manufacturer as well as reduces fuel consumption and the environmental impacts of the manufacturing process.

The bill seeks to establish a national smart manufacturing plan and to provide support for small- and mediumsized manufacturers - companies with fewer than 500 employees at the plant site, gross annual sales of less than $\$ 100$ million, and annual energy bills between $\$ 100,000$ and $\$ 2.5$ million. The focus on this segment of the manufacturing industry was explained in Senator Shaheen's news release announcing the introduction of the SMLA, which said that small- and medium-sized manufacturers often lack the staff resources, expertise, and capital needed to implement smart manufacturing technologies.

Since the introduction of the SMLA, the US Senate Committee on Energy and Natural Resources (ENR) has put together a comprehensive energy bill that includes key provisions from the SMLA. The omnibus bill, titled the Energy Policy Modernization Act (EPMA) of 2015 (S. 2012), is the culmination of four committee hearings where 114 bills were considered and discussed. Several of these bills were incorporated, in part or whole, in the EPMA, a comprehensive energy package that according to the ENR committee "represents the common ground that exists for modernizing our energy policies on efficiency, infrastructure, supply, accountability, and reauthorizing conservation programs."

The EPMA includes two provisions from the SMLA. The first of these seeks to expand the US Department of Energy's (DOE's) existing Industrial Assessment Centers (IACs) to incorporate smart manufacturing technologies and practices. The IACs have offered energy assessments to small- and medium-sized

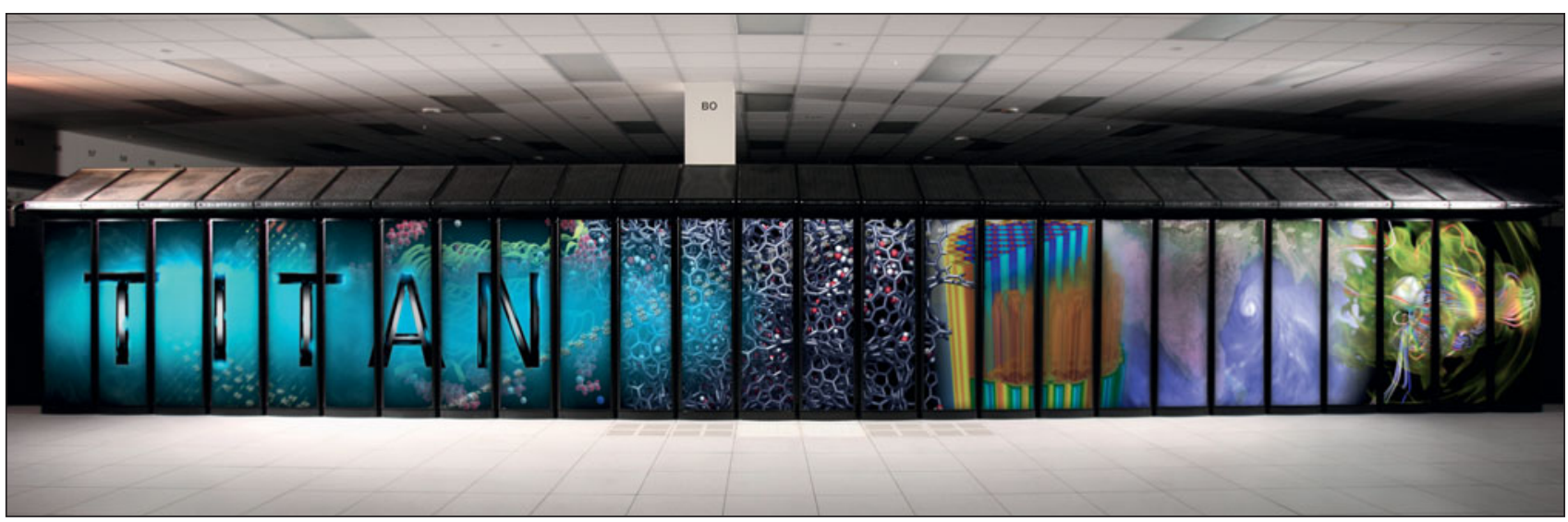

The passage of the SMLA would grant small- and medium-sized manufacturers greater access to supercomputers like the Titan (pictured). These computers and the experts who run them play an integral role in smart manufacturing by helping identify areas that can be upgraded to make the manufacturing process more efficient. Photo courtesy of Oak Ridge National Laboratory, US Department of Energy. 
manufacturers for nearly 40 years, and the bill's inclusion of smart manufacturing solutions within the assessment program seeks to produce even greater energy savings, waste reductions, and improvements in manufacturing productivity.

The second provision from the SMLA that is included in the EPMA addresses access for small- and medium-sized manufacturers to DOE national laboratories, with specific focus on high-performance computing facilities. These facilities house some of the world's fastest supercomputers, which are capable of running complex simulations that could be used to optimize manufacturing practices. The bill mandates a study be conducted to identify ways by which DOE can increase access to high-performance computing facilities, and directs the Secretary of Energy to facilitate access for smalland medium-sized manufacturers.

The EPMA was passed out of the ENR committee and placed on the Senate Calendar on September 9, 2015. The inclusion of the key provisions from the SMLA in the EPMA signals bipartisan support for these measures. In addition, while it used to be common practice to incorporate a large number of energyrelated bills into a comprehensive package for Senate consideration every few years, the recent increase in partisan tension has derailed this process. The Energy Independence and Security Act of 2007 (Pub. L. 110-140) was the last successful omnibus energy bill, and in recent years the ENR committee has not even attempted to put together a comprehensive energy package. While the existence of the EPMA and its success through the committee process shows that it is now possible to find common ground on some of the important energy issues facing the country, it is impossible to predict whether these issues will be considered a priority, especially as the 2016 elections draw near.

The Materials Research Society (MRS) was asked by Senator Shaheen's office to support the SMLA — "a direct result of the MRS's continued presence and interactions on the Hill," said Damon Dozier, MRS Director of Government Affairs. As with any legislation MRS considers supporting, the Government Affairs Committee (GAC) consulted with executive leadership to "consider the impact on and value to the materials research community," said Duane Dimos, GAC Policy Subcommittee Chair. MRS provided a letter of support for the SMLA stating, "the adoption of smart manufacturing as outlined in your legislation can add a real benefit to the improvement of industrial processes ..." and offered to provide further input as the bill proceeded through the legislative process.

"Materials research is critical to enabling the essential advances in materials design, processing, and control necessary for smart manufacturing," said Todd M. Osman, MRS Executive Director. While the bill does not specifically fund materials research, Osman said, "MRS is encouraged to see strong support for smart manufacturing by key members of Congress, which we anticipate will broaden awareness of the role of materials research in advanced and high-tech manufacturing."

Jennifer A. Nekuda Malik
Australia's national outlook is bright www.CSIRO.au/nationaloutlook

A report has found that Australia is vell placed to secure prosperity over the coming decades despite the challenges of an uncertain and possible resource-constrained future.

However, this prosperity is not a given - instead Australia's future will be shaped by innovation and technology.

According to Australia's national science agency CSIRO, the Australian National Outlook, released recently, is the most comprehensive quantitative analysis yet of the interactions between economic growth, water-energy-food use, environmental outcomes, and living standards in Australia.

CSIRO Executive Director Alex Wonhas said National Outlook focused on the "physical economy" that contributes to about $75 \%$ of natural resource use and produces about $25 \%$ of Australia's gross domestic product (GDP).

"The National Outlook is a first attempt to understand and analyze the connections in Australia's physical environment many decades into the future," Wonhas said.

"It has a particular focus on understanding two aspects: The 'waterenergy-food nexus' and the prospects for Australia's materials- and energyintensive industries."

National Outlook finds a number of key insights and potential opportunities across the Australian economy. And as Australia's population grows, so too does water demand.

"Despite projections of a doubling of our water use, Australia could meet this growth as well as enhance urban water security and avoid increased environmental pressures through increased water recycling, desalination, and integrated catchment management," Wonhas said.

The results of CSIRO's National Outlook show that energy and other resources could remain a pillar of the Australian economy well into the future, and that energy-intensive industries could be well positioned to continue to grow, even in scenarios where the world is taking global action to significantly limit greenhouse gas emissions.

"The key to this success will be innovation and application of smart technologies," Wonhas said. "We hope the National Outlook will help Australia chart its future in an increasingly complex and interconnected world."

The National Outlook explores over 20 possible futures for Australia out to 2050 against the backdrop of the past 40 years. 